\title{
Del desastre de Getares a la victoria del Salado: la crítica situación de la zona del Estrecho en 1340
}

\author{
From the disaster of Getares to the victory of El Salado: \\ The critical situation of the straits of Gibraltar
}

\author{
MANuel LÓPeZ Fernfández*
}

\begin{abstract}
RESUMEN
A comienzos de 1340 se presagiaba en el Estrecho de Gibraltar una ofensiva meriní. Castilla contaba con una flota insuficiente para frenar a los musulmanes y el reino de Aragón, que también colaboraba en la vigilancia de aquellas aguas, había reducido sus efectivos al mínimo. Así las cosas, en el mes de abril la flota castellano-aragonesa sufrió una aplastante derrota en la Ensenada de Getares, a la que siguió el traslado de un importante contingente marroquí a la Península y el posterior cerco a Tarifa. Alfonso XI, con la ayuda del rey de Portugal, acudió a descercar esta plaza y acabó imponiéndose en la batalla del Salado. Las consecuencias posteriores de esta victoria resultaron fundamentales para el dominio del Estrecho.
\end{abstract}

\section{PALABRAS CLAVE \\ Alfonso XI. Abu l-Hasan. Estrecho de Gibraltar. Ensenada de Getares. Batalla del Salado.}

\begin{abstract}
At the beginning of 1340, a Merini attack was expected in the Straits of Gibraltar. The kingdom of Castile had an inadequate navy to stop the Muslims, and the Aragón's kingdom, which also helped in the surveillance of that sea area, had reduced his troops to the minimum. In April, the Castilian - Aragonese navy suffered a crushing defeat in the Getares inlet, followed by the pass of one important Moroccans' contingent to the Peninsula and the later siege to Tarifa. Alfonso XI, with the help of the King of Portugal, came to free the city from the siege, and later on he won the Salado Battle. The subsequent consequences of this victory were essential for the Straits control.
\end{abstract}

\section{KEY WORDS}

Alfonso XI. Abu l-Hasan. Straits of Gibraltar. Getares' inlet. Salado's battle.

* UNED. (C.A. de Algeciras) - Instituto de Estudios Campogibraltareños. 


\section{ANTECEDENTES POLÍTICO-MILITARES}

Sin temor a equivocarnos, podemos decir que 1340 fue un año crucial para el reino de Castilla en su lucha por el control de las aguas Estrecho; y también lo fue en lo que se refiere al mantenimiento del dominio que ejercía por entonces sobre Tarifa, un punto vital de la orilla Norte de este brazo de mar que separa África de Europa. En realidad, la pugna entre meriníes y castellanos por el control de las aguas del Estrecho había comenzado desde el momento mismos que estos últimos se hicieron con Tarifa en 1292, sabedores de la importancia estratégica de la plaza desde el punto de vista militar ${ }^{1}$ y quizá también del comercial ${ }^{2}$. Desde entonces, los enfrentamientos en el mar se dieron con suerte varia para ambos rivales y si el intento de apoderarse de Algeciras terminó en un rotundo fracaso para Fernando IV, no debemos olvidar que en septiembre de 1309 los castellanos consiguieron hacerse con Gibraltar.

No hubo cambios geopolítico apreciables en los años posteriores, pero en 1331 comenzaron a cambiar las relaciones políticas de los meriníes con sus vecinos, coincidiendo con la llegada de Abu I-Hasan al trono de Fez. El nuevo sultán se había fijado unos ambiciosos objetivos en el Magreb y, concretamente, al otro lado del Estrecho pretendía aumentar sus dominios para monopolizar así los beneficios del importante comercio transahariano ${ }^{3}$. La primera demostración de las intenciones de Abu I-Hasan se produjo a primeros de 1333 cuando el infante Abu Malik cruzó el Estrecho y puso sitio a la plaza de Gibraltar ${ }^{4}$ atendiendo la petición de ayuda que le hiciera el rey Muhhamad IV de Granada 5 . Abu Malik cercó la fortaleza del Peñón y consiguió hacerse con la misma el 21 de junio de aquel año sin que el rey de Castilla pudiera ayudar por tierra a los sitiados ${ }^{6}$. Cuando Alfonso XI llegó con su hueste frente a Gibraltar trató de recuperar la fortaleza, pero la llegada del ejército granadino a Sierra Carbonera hizo que la situación se estabilizara y finalmente se concertaron unas treguas el día 24 de agosto; treguas que posteriormente fueron

\footnotetext{
1 No olvidemos que el proyecto inicial de los castellano fue hacerse con el puerto de Algeciras. Sin embargo, finalmente decidieron poner sitio a Tarifa porque «era la mar más estrecha alli, e que había alli mejor salida para los caballos cuando los moros pasasen aquende». Así se explican las razones para poner sitio a Tarifa en la Crónica del rey don Sancho el Bravo. Véase en «Crónicas de los reyes de Castilla», volumen $n^{\circ}$ LXVI de la Biblioteca de Autores Españoles. Ediciones Atlas. Madrid, 1953, p. 86.

2 Parece éste un aspecto secundario, pero tengamos en cuenta que con anterioridad los genoveses habían iniciado el paso por el Estrecho con mercancías rumbo al Mar del Norte. Se iniciaba así la reapertura de la vía comercial conocida como «ruta de Poniente».

3 Abu l-Hasan pretendía reunificar el Magreb, pero además quería hacerse con el reino de Tremecén porque éste incrementaba por entonces su importancia en el comercio con las regiones transaharianas en detrimento de Fez, así en LÓPEZ PÉREZ, María Dolores: La Corona de Aragón y el Magreb en el siglo XIV (1331-1410). CSIC.. Institución Milá y Fontanals. Barcelona, 1995, pp.55-58.

${ }^{4}$ MANZANO RODRÍGUEZ, Miguel Ángel: La intervención de los benimerines en la Península Ibérica. CSIC. Madrid, 1992, pp. 222-223.

5 Según Al-Jatib, fue en el mes de septiembre cuando el rey de Granada hizo el viaje a Fez. Así en AL-JATIB, Ibn: Historia de los reyes de la Alhambra. El resplandor de la luna llena. Estudio preliminar de Emilio Molina López. Traducción e introducción de José María Casciaro Ramírez. Granada, 1998, p. 101.

${ }^{6}$ Más detalles sobre este asunto se pueden ver en nuestro trabajo: «El itinerario del ejército castellano para descercar Gibraltar», en Espacio Tiempo y Forma, n 18. UNED. Madrid, 2005, pp. $185-207$.
} 
ratificadas por Castilla y Marruecos en marzo de 1334 y a las que se unió Aragón al año siguiente ${ }^{7}$.

Una vez firmados estos acuerdos con Castilla y Aragón, Abu I-Hasan emprendió la conquista del reino vecino de Tremecén y para finales de abril de 1337 se había hecho con la capital de este reino. Para entonces, Pedro IV de Aragón ya tenía noticias de las intenciones de Abu I-Hasan con respecto al reino de Valencia y tomó medidas para su defensa costera ${ }^{8}$ sin poder evitar que, en noviembre de aquel año, algunos lugares de la costa valenciana fuesen víctimas de un asalto marroqui ${ }^{9}$. En los primeros meses de 1338 aumentaron los rumores sobre los preparativos benimerines y de la intención que tenía el sultán de colocar al infante Abu Malik al frente de los ejércitos que habían de pasar a la Península. Pero como este paso no podía darse sin levantar las sospechas de Castilla, aprovechó la circunstancia de la renovación de las treguas con este reino para enviar un fuerte contingente bajo el pretexto de que formaban parte de la embajada del emir Abu Malik ${ }^{10}$. Pero aquella maniobra no pasó desaperciba para los castellanos y, temiendo que se repitiera el hecho, el rey de Castilla mandó a su almirante que fuese a vigilar las aguas del Estrecho. Por ello, el almirante Jofre Tenorio salió de Sevilla después de armar su flota y «... se fue contra Gibraltar» vigilando con sus naves que los musulmanes no pasaran más tropas ni pertrechos militares ${ }^{11}$.

A finales del mes de abril de 1338 seguían el reino de Aragón los rumores con respecto a los preparativos que llevaban a cabo los benimerines; por esa razón, a principios de mayo, el rey Pedro el Ceremonioso intentará llegar a un acuerdo con Abu I-Hasan ${ }^{12}$, aunque con anterioridad había pretendido acercarse a Castilla con la finalidad de aunar esfuerzos entre los dos reinos ante las previsibles intenciones del sultán meriní. Según nos dice Jerónimo de Zurita ${ }^{13}$, el día 13 de abril Pedro IV había enviado como embajador ante el rey de Castilla a Pedro Ruiz de Azagra con la intención de limar asperezas en el desencuentro existente entre Castilla y Aragón para llegar a un acuerdo frente a los musulmanes de Marruecos. De estas dos propuestas de paz iniciadas por Aragón sólo fructificó la que se intentó con CastiIla, aunque para llegar a un acuerdo se hubo de esperar casi un año hasta solucionar los problemas que doña Leonor, la hermana del rey de Castilla, tenía con el monarca aragonés ${ }^{14}$. Una vez superado este escollo, el rey de Aragón dio poderes

7 LÓPEZ PÉREZ, : La Corona de Aragón..., p. 60. Según esta autora, Alfonso IV lo ratificó también en junio de 1335 después de enviar sus propios embajadores a Granada.

${ }^{8}$ SEVILLANO I COLOM, Francesc: «Crisi hispano-musulmana: un decenni crucial en la reconquista (1330-1340)", en Estudis d'Historia Medieval, vol. III. Barcelona, 1970, p.58.

9 Ibidem..., p. 60.

10 MANZANO RODRÍGUEZ : La intervención..., p. 238-239.

11 Gran Crónica de Alfonso XI. (En adelante, Gran Crónica). Preparada por Diego CATALÁN. Editorial Gredos. Madrid, 1976, tomo II, capítulo, CCXLIII.

12 SEVILLANO I COLOM: «Crisi hispano-musulmana...»,pp. 10-13. El autor aporta aquí dos documentos que así lo demuestran.

${ }_{13}$ ZURITA, Jerónimo de: Anales de la Corona de Aragón. Edición de Ángel Canella López. Zaragoza, 1970, tomo III, p. 456.

${ }^{14}$ La infanta Leonor de Castilla era la segunda esposa de Alfonso IV de Aragón y a la muerte de éste tuvo serios enfrentamientos con el heredero del trono, Pedro IV, hijo de un anterior matrimonio del difunto monarca. 
a Gonzalo García para que se desplazara a Castilla y llegara a un acuerdo en la cuestión del Estrecho con el rey castellano. El representante de este último fue su canciller, Fernán Sánchez de Valladolid, y el día 1 de mayo de 1339 se llegó a un acuerdo entre ambas partes ${ }^{15}$; acuerdo que se conoce como Tratado de Madrid y mediante el cual se comprometían Castilla y Aragón a prestarse mutuo apoyo en la vigilancia del Estrecho. En el acuerdo citado se reconocía que Castilla tenía firmadas unas treguas con Marruecos y Granada hasta marzo de 1342, y Aragón con Granada hasta abril del mismo año. Se decía también que, siendo necesaria la vigilancia del «estrecho de Tarifa» por una flota conveniente, Castilla se comprometía a enviar 20 galeras en los meses de verano - de junio a septiembre-, en tanto que Aragón enviaría la mitad; y esta misma proporción se guardaría entre los meses de octubre a mayo, pero la aportación respectiva de galeras se reducía a 8 en el caso de Castilla y 4 por parte de Aragón.

Como consecuencia de este acuerdo el almirante aragonés Gilabert de Cruilles salió rumbo al Estrecho con la flota que pudo reunir en Valencia, a mediados del mes de junio, cuando la tensión había crecido hasta el punto que las hostilidades eran abiertas entre cristianos y musulmanes. Lo eran porque los últimos no dejaron de pasar y los primeros comenzaron a apresar algunas embarcaciones musulmanas, respondiendo éstos con las mismas medidas. El enfrentamiento se daba por tierra y mar cuando el almirante aragonés se presentó en Sevilla para recibir instrucciones con respecto a su función en el Estrecho ${ }^{16}$. Y no tardó en demostrarse la eficacia de aquella vigilancia conjunta en estos mares porque a las fuerzas de Abu Malik comenzaron a faltarle provisiones ${ }^{17}$. Para subsanar este déficit se hallaba preparada en Ceuta una flota para cruzar el Estrecho cuando ésta fue deshecha por los efectivos navales de Aragón el día 7 de septiembre. Esta ofensiva de Cruilles sobre Ceuta debió ser la gota que colmó el vaso de la paciencia del infante Abu Malik, quien ordenó efectuar una algara sobre Medina Sidonia con la finalidad de robar todo el ganado que pudiesen y graduar al mismo tiempo la capacidad de respuesta de los castellanos. Como éstos no contestaron militarmente, y Abu Malik supo que el rey de Castilla no estaba en Sevilla, posiblemente en los días finales de aquel mes de septiembre de 1339 dirigió en persona otra expedición más numerosa - le acompañaban en esta ocasión gente de Ronda-, que pasando por Medina Sidonia llegó hasta Jerez pretendiendo hacerse con las provisiones necesarias antes que llegara el invierno.

Después de asentar en las proximidades de esta última villa, mandó a parte de su gente que se desplazaran para saquear Lebrija y al ser rechazados aquí prosiguieron su avance hasta llegar al "Bodegon de Pascual el Rruvio", cerca de Dos

15 Véase en, Colección de Documentos Inéditos del Archivo General de la Corona de Aragón (en adelante, CODOIN. ACA.). Publicados por Próspero de Bofarull y Mascaró. Barcelona 1851, tomo VII, documento $\mathrm{n}^{\circ} 5$.

${ }^{16}$ El almirante se presentó en Sevilla al rey de Castilla cuando éste había vuelto de una incursión por Ronda y Antequera. Por su parte el maestre de Santiago derrotó en Siles, cerca de Segura de la Sierra, a los granadinos cuando éstos intentaban arrebatarle la plaza fuerte.

17 Gran Crónica, tomo II, p. 270 
Hermanas ${ }^{18}$. No tardaron los hombres del concejo de Sevilla y otros señores de fortalezas fronterizas en reunirse en Utrera y salir en busca de los moros, no sin antes mandar aviso al maestre de Alcántara que estaba en Écija como Adelantado Mayor de la Frontera y que acababa de regresar de una incursión por Alcalá de Benzayde, hoy Alcalá la Real. Los efectivos que tenía el Maestre, a pesar de la lluvia que caía - según dicen las crónicas ${ }^{19}$-, se pusieron en marcha y caminando de día y de noche se reunieron con los que venían de Utrera en un lugar al Norte de Arcos. Al día siguiente encontraron a los musulmanes que venían siguiendo desde cerca de Sevilla y con la ayuda de la gente de Arcos consiguieron derrotarlos, apoderándose de todo el ganado que llevaban.

Abu Malik, cuando terminó el saqueó de la zona de Jerez, levantó su campamento y buscó el camino que, con dirección a Algeciras, pasaba por las proximidades de Alcalá de lo Gazules. Pero a esas alturas ya estaban detrás de sus pasos todos los efectivos fronterizos cristianos pues en las proximidades de Arcos se reunieron los del concejo de Écija con aquellos que habían derrotado a los musulmanes, y con posterioridad se sumaron a éstos los de Jerez. Decididos abiertamente a atacar todos juntos al emir Abu Malik, recibieron información desde Alcalá que el «ynfante Abomelique yva esta noche a dormir a la Vega de Pagana, çerca del rrio de Patrite; e que por los muchos ganados que levaua e por las grandes luvias que hazia que no podia andar sino pequeñas jornadas, e que si ellos anduviesen aquella noche, que alli los alcançarian". Como era mucho el entusiasmo de aquella gente y no menor el botín a recuperar, se pusieron en marcha y anduvieron toda la noche llegando cerca del real de los musulmanes un poco antes del amanecer ${ }^{20}$, "e como quiera que la noche hazia muncho escura e con agua, vieron las candelas e los fuegos en el rreal de los moros".

Abundan las crónicas cristianas ${ }^{21}$ en los detalles de aquella jornada y por ellas sabemos que los de Castilla prefirieron esperar la luz del día antes de iniciar el ataque. Pero estuvo a punto de fracasar el efecto sorpresa, porque los peones, subidos en unos montes cercanos, levantaron con sus voces las sospechas de algunos musulmanes. Por tal razón un grupo de éstos subió a los caballos y atacaron a la gente de la frontera; de manera que unos y otros se enfrentaron en las cercanías de un río sin que aquel grupo de islamitas pudieran frenar el ataque de los cristianos que, por todas partes, penetraron en el campamento benimerí poniendo en franca desbandada a sus ocupantes. Cogido por sorpresa, el infante Abu Malik sufrió varias heridas en aquella refriega, pero aún le quedaron fuerzas para em-

18 El bodegón de Pascual Rubio de las crónicas castellanas se conoce todavía con el topónimo «El Rubio» y se corresponde con una finca así llamada en el actual término municipal de Dos Hermanas.

19 Así en Gran Crónica, tomo II, p. 274. La distancia menciona aquí ronda los 77 kilómetros. No debe sorprendernos que las crónicas recoja esta anécdota porque, a todas luces, fue una marcha fuera de lo corriente y obligada por las circunstancias.

20 Gran Crónica, tomo II, p. 277.

21 Aunque seguimos el asunto y citamos por Gran Crónica, no estaría mal decir que la Crónica del rey don Alfonso el Onceno, (en adelante, Crónica) habla de la derrota del infante Abu Malik en su capítulo CC. Véase en «Crónicas de los reyes de Castilla», volumen $n^{\circ}$ LXVI de la Biblioteca de Autores Españoles. Ediciones Atlas. Madrid, 1953. 
prender la huida con dirección a la sierra que se interponía entre las Vegas de Pagana y Algeciras. En esta sierra consiguió esconderse en «vna breña de çarças çerca de un arroyo» donde terminó sus días.

No sabemos como pudo enterarse el cronista de los detalles relativos a los últimos momentos de Abu Malik, pero no queremos dejar de señalar aquí que aquella victoria cristiana superó el ámbito cronístico y alcanzó el cinegético ${ }^{22}$ teniendo una amplia repercusión en toda la comarca y dando origen, en las cercanías Alcalá de los Gazules, al santuario mariano de la Virgen de los Santos en recuerdo de aquella batalla ${ }^{23}$. Pero tan importante como lo anterior resulta señalar que en la toponimia de este pueblo gaditano se conserven nombres tan significativos como Arroyo de la Pelea y Mata del Tuerto, que de alguna manera vienen a señalarnos la ubicación de lugares relacionados directamente con los decisivos momentos de aquel encuentro campal. Y como el topónimo Mata del Tuerto ${ }^{24}$ corresponde a un montículo de unos 90 metros de cota situado entre el río Alberite y el Arroyo del Tramposo —llamado de las «Trompas» en la Edad Media ${ }^{25}$-, cabe pensar que fue junto a éste donde Abu Malik encontró la muerte en un día de finales de octubre ${ }^{26}$ de 1339.

\section{LA DERROTA NAVAL DE GETARES Y SUS CONSECUENCIAS}

Por entonces, finales de octubre de 1339, hacía poco más o menos de un mes que había muerto en las proximidades de Algeciras el almirante de la flota aragonesa, Gilabert de Cruilles. No conocemos los detalles con precisión, pero si seguimos a Jerónimo de Zurita ${ }^{27}$ - qué sí debió leer algún documento al respecto ${ }^{28}$ podemos saber que el almirante fue herido por una saeta cuando realizaba algún ataque en tierra, no en una confrontación naval como pudiera parecer más lógico.

22 En el Libro de la Montería de Alfonso XI, cuando se describen los cazaderos de Alcalá, se dice: «El arroyo de Miguel Perez de las Plegueras es buen monte de puerco en todo tiempo. Et es la una bozería por el çerro que salieron los moros quando fue desbaratado Abomelique, fasta do da en el valle donde se comiença la breña; et es la otra bozería por la ladera de la Cabeza de las Trompas...".

23 FERNÁNDEZ GÓMEZ, Marcos: «La villa de Alcalá de los Gazules (Cádiz), un enclave fronterizo del reino de Sevilla en la Baja Edad Media», en En la España Medieval, n 18. Madrid, 1985, p. 216.

${ }_{24}$ Citamos por el mapa del Servicio Geográfico del Ejército, escala 1: 50.000, hoja 1070 del año 1974.

25 Véase así en cualquier edición del «Libro de la Montería de Alfonso Xl» cuando habla de los cazaderos de Alcalá de los Gazules.

${ }_{26}$ En la crónica del rey Pedro I se habla de que murió el día 20 de octubre. Pero no deja de señalarse aquí, en nota a pie, que también existe una referencia en otra edición de dicha crónica en la que se dice que murió el día 28 del citado mes. Véase este detalle en "Crónica del rey don Pedro", dentro de las “Crónicas de los reyes de Castilla», volumen $n^{\circ}$ LXVI de la Biblioteca de Autores Españoles. Ediciones Atlas. Madrid, 1953, p. 402.

27 ZURITA: Anales de la Corona de Aragón. Tomo III, p. 483.

28 Los datos que aquí proporciona Zurita con respecto al almirante Gilabert de Cruilles, así como el relato de las circunstancias familiares que afectaron a la familia después de su muerte, nos hacen pensar que estaba bien informado con respecto a este asunto. Por nuestra parte sólo decir que hemos tratado de encontrar el documento en cuestión, pero no hemos tenido la suerte de encontrarlo. 
Y surge aquí la consiguiente pregunta, ¿en qué lugar de las proximidades de Algeciras pudo darse este ataque? De entrada, podemos considerar que pudo ser cualquier lugar si tenemos en cuenta que los marinos castellano-aragoneses debieron ver la salida del numeroso contingente que, de Algeciras y al mando de Abu Malik, tomó el camino hacia Medina Sidonia y Jerez ${ }^{29}$. La situación debió parecerles propicia para hacerse con algún lugar del que pudieran estar necesitados; porque sinceramente no creemos que los componentes de la flota fueran tantos como para empeñarse en alguna demostración de fuerza que intimidara a los musulmanes algecireños.

Así que, teniendo en cuenta lo anterior, y considerando que la flota castellanoaragonesa estaban muy necesitada de un fondeadero cercano al lugar donde estaban operando - para que el personal las misma pudiera «refrescar» y donde las naves encontraran cierta protección sin abandonar aquella labor de vigilancia que le había sido encomendada-, nos inclinamos a creer abiertamente que el objetivo de aquellos hombres no fue otro que hacerse con las playas del fondeadero de Getares, lugar que reunía las condiciones buscadas ya que dicha ensenada está situada en la entrada de la Bahía de Algeciras y desde donde se podía divisar a simple vista el puerto de Gibraltar, además de posibilitar el control de todo movimiento naval que se hiciera desde Ceuta sobre este puerto, o el Algeciras. Pero hacerse con las playas de la ensenada de Getares, donde desembocan algunos arroyos que baja de la cercana sierra, suponía hacerse con el control de las altura inmediatas que dominan el fondeadero para proporcionar al campamento que allí se instalara una cierta seguridad.

Como hemos dicho, debían correr por entonces los días finales de septiembre y las galeras aragonesas, o la mayor parte de ellas, estaban a punto de volver a Valencia porque a mediados de octubre finalizaba el servicio que debían realizar lejos de sus bases ${ }^{30}$. Por tanto, se presentaba un invierno difícil para los que quedaran en el Estrecho, motivo por el que nos inclinamos a pensar que antes de la marcha de las naves aragonesa los almirantes acordaron hacerse con las playas del fondeadero aprovechando la disminución de efectivos terrestres en Algeciras. Por eso creemos que pudo ser en esta acción ofensiva - desembarco y consolidación de la posición- la que costó la vida al almirante de la Corona de Aragón y por ello, el día 29 de septiembre según consta documentalmente ${ }^{31}$, seis galeras aragonesas abandonaron el Estrecho llevando el cuerpo del que había sido su almirante y dejando las cuatro galeras restantes al mando de Dalmau de Cruilles $^{32}$.

29 La Crónica habla hasta de 6.000 hombres.

30 No podemos entrar en detalles por razones de espacio, pero diremos que en estos cuatro meses se contaba el tiempo de los viajes de ida y vuelta. Por otro lado, la mayor parte de las salidas de las naves aragonesas que operaron en el Estrecho se acordaron para cuatro meses. Cuando, por alguna situación concreta, debieron prolongar su estancia más del tiempo señalado se le hizo saber con antelación al almirante.

${ }_{31}$ El rey castellano escribió al aragonés informándole que el día de san Miguel sólo quedaban en el Estrecho cuatro galeras aragonesas y que desde entonces no recibía ayuda alguna de Aragón. Así en CODOIN. ACA., documento $n^{\circ} 14$.

${ }^{32}$ Estos datos se conocen al sumar la información que nos proporciona Jerónimo de Zurita con los datos que constan en otro documento editado por Próspero de Bofarull: CODOIN. ACA., $\mathrm{n}^{\circ} 15$. 


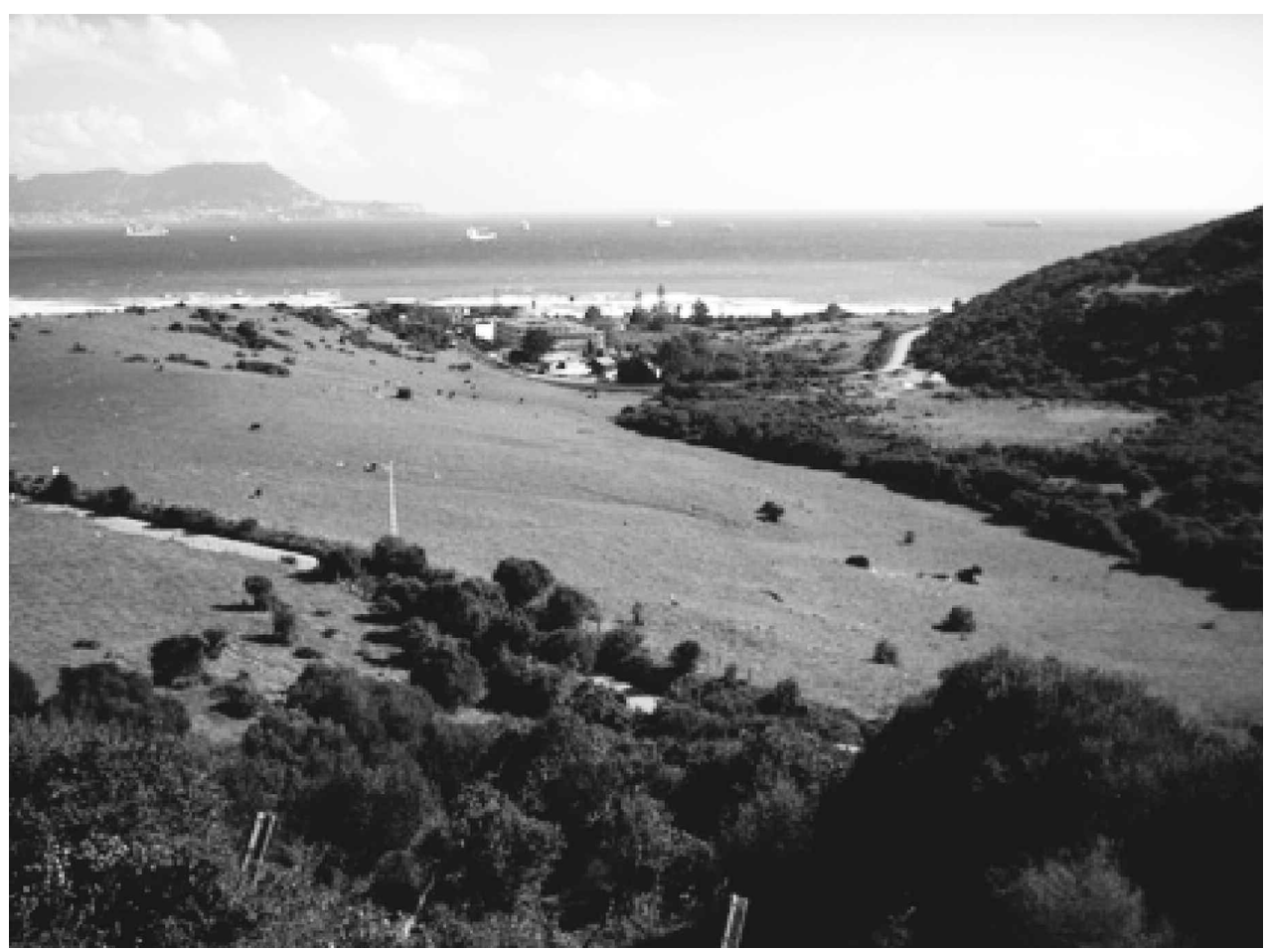

La fotografía muestra el fondo de la Ensenada de Getares. En primer plano, la zona de la desembocadura del Arroyo del Lobo.

No sabemos que ocurriría con el uso de las playas del fondeadero de Getares cuando retornaron a Algeciras los derrotados hombres del infante Abu Malik, pero sí conocemos que la noticia de la muerte de éste llegó a la otra costa del Estrecho y que sus ecos hicieron resonar allí los tambores de guerra. Los preparativos bélicos se intensificaron en todos los frentes y prioritariamente en aquellos aspectos relacionados con el mar, pues el sultán necesitaba contar con efectivos navales suficientes para desbloquear el Estrecho y transportar a sus fuerzas hasta los puertos de la orilla Norte del mismo. A tales efectos, Abu I-Hasan comenzó sus preparativos en Argel $^{33}$ al tiempo que pidió ayuda a todos sus aliados ${ }^{34}$ y se desplazó con posterioridad a Ceuta ${ }^{35}$ donde se fue concentrando la armada cuyo mando entregó al gobernador de esta ciudad, Mohammed Ibn Ali I-Azefi. Sin embargo, antes de

${ }^{33}$ IBN MARZUQ : El Musnad : hechos memorables de Abu l-Hasan sultán de los benimerines. Estudio traducción y anotaciones de María Jesús Vigueras. Instituto Hispano Árabe de Cultura. Madrid, 1977, pp. 140-141. Relata aquí Ibn Marzuq cómo los de Argel se resistían a intervenir comos arqueros en la armada que se estaba preparando

34 Se dice en MANZANO: La intervención... p. 249, que el sultán reunió embarcaciones procedentes de Trípoli, Gabes, Yerba, Túnez, Bona y Bujía, además de las que envió el rey granadino Yusuf I.

35 IBN KHALDOUN: Histoire des Berberes. Traducción del Barón de Slane. Librairie Orientaliste. Paris, 1978, p. 230. 
llevar a cabo la operación decisiva — tal vez a principios de 1340—, una parte de aquella flota burló la vigilancia de la flota castellana y llevó a la Península los efectivos suficientes para hacer una incursión por la misma comarca que anteriormente había saqueado Abu Malik, y que tuvo el mismo final cuando los concejos de Jerez y Arcos, ayudados por gente del rey, le hicieron frente ${ }^{36}$.

A mediados de marzo de 1340 inició la flota musulmana el paso del Estre$\mathrm{cho}^{37}$ con una maniobra evasiva en la que simularon dirigirse al interior del Mediterráneo ${ }^{38}$. Al parecer, aquel tipo de maniobra fue la razón argumentada por el almirante Jofre Tenorio para no entrar en combate; pero lo que parece más cierto es que no atacó porque poco hubiera podido hacer frente aquella flota cuyos efectivos superaban con largueza el centenar de naves de guerra ${ }^{39}$. El almirante de Castilla, según los datos que manejamos, no contaba por entonces con más de 28 naves de guerra - sumando galeras y leños e incluyendo las cuatro galeras de Aragón ${ }^{40}$ - así que dejaría navegar aquella flota con dirección a Berbería sin oponer resistencia alguna. Pero no tardaron los musulmanes en cambiar de rumbo y dirigirse hacia las costas andaluzas para enlazar con la fuerzas terrestres que habían salido de Gibraltar; fuerzas que protegieron a la flota desde tierra hasta su arribada en el mismo «monte de Gibraltar» según dicen las crónicas. Para cuando Jofre Tenorio quiso reaccionar era demasiado tarde porque la flota de Abú I-Hasan ya estaba en el Peñón, por lo que se mantuvo a la espera varios días hasta que los elementos vinieron en ayuda de los musulmanes al levantarse un fuerte temporal de Levante que le obligó a buscar refugio en Tarifa ${ }^{41}$. Tal situación fue aprovechada por el almirante de Ceuta para llevar la flota bajo su mando desde Gibraltar al puerto de Algeciras ${ }^{42}$ sin que la castellana pudiera evitarlo.

Se puede decir que con la llegada de la flota al puerto de Algeciras los musulmanes habían alcanzado el primero de sus objetivos; el segundo debía ser combatir a la flota castellana y hacerse con sus bases hasta que la misma supusiera el menor obstáculo posible en el Estrecho para sus planes de seguir pasando efectivos militares a la Península. Y fue entonces cuando Jofre Tenorio envió información al rey de Castilla de la nueva situación que se vivía en aquellas aguas, que-

36 Gran Crónica..., tomo II, p. 301-302.

37 Las crónicas castellanas dicen que el paso del Estrecho lo realizaron los musulmanes de noche. Con respecto a la concreción de la fecha, hay que suponerla por la serie de acontecimientos que transcurrieron entre la maniobra de los islamitas y la batalla del día 8 de abril.

${ }_{38}$ De este detalle sólo se habla en la Crónica, p. 307, cuando dice que un capitán de las naves castellanas informó al mismo Alfonso XI de la crítica situación en el Estrecho.

39 Las crónicas castellanas hablan hasta de «dozientas e cincuenta velas» de las cuales 60 eran galeras. Gran Crónica..., tomo II, p. 312. Ibn al-JATIB: Historia de los reyes..., p. 115, dice que ciento cuarenta naves de guerra.

40 En el momento del enfrentamiento definitivo, el día ocho de abril, sabemos que tenía 28 galeras cuando con anterioridad había perdido una de ellas como consecuencia de un temporal y recibido 14 de refuerzo: las ocho primeras procedentes del Puerto de Santa María y luego otras seis que se armaron en Sevilla.

41 Entonces fue cuando la flota castellana perdió la galera Santa Ana.

42 Gran Crónica...., tomo II, p. 311. 
jándose del escaso potencial de la flota a su mando 43 . Alfonso XI le envió entonces seis galeras que se habían armado en las atarazanas de Sevilla y con ellas el número de unidades de la flota castellana se elevó hasta 33; eso sin contar las naves que engrosaban la misma y que, según un documento de aquellas fechas ${ }^{44}$, debían alcanzar el número de 19 embarcaciones. Con estos refuerzos, el almirante «mando mover de ally [suponemos que de Tarifa, donde se habían refugiado durante el temporal] e fue fincar las ancoras en el puerto de Algezira» " ${ }^{45}$, donde permaneció tres días esperando que la flota musulmana salieran a darle batalla. Pero éstos se sintieron seguros en su base teniendo a toda la flota unida -táctica muy utilizada en aquella época donde los combates se decidían sobre las cubiertas de las embarcaciones-, y decidieron no salir a combatir esperando una mejor oportunidad; circunstancia por la que la flota castellana hubo de retirarse hasta un lugar donde sus hombres pudieran reponerse. $Y$ surge aquí la lógica pregunta, ¿hacia dónde pudo retirarse la flota al mando del almirante de Castilla?

El fondeadero que buscamos debía tener capacidad para 52 embarcaciones si se quería mantener la flota unida, pues esto era lo más aconsejable si se quería obtener la máxima capacidad de respuesta. Por ello se podía pensar a primera vista que pudiera servirle cualquiera de los buenos fondeaderos existentes en la costa Norte de la Bahía ${ }^{46}$, el de Palmones, el de Guadarranque, o Puente Mayorga, pero no creemos que el almirante los utilizara en esta ocasión porque estando anclada en Algeciras una flota más numerosa que la suya, podía ocurrir que el enemigo le cortara la retirada hacia Tarifa en un momento dado. Así que debemos buscar otro emplazamiento más cercano al Estrecho que le permitiera mantener abiertas las líneas de comunicación con Tarifa; en este sentido no podemos tener en cuenta la Ensenada del Tolmo ya que su capacidad no daría para proteger una flota de la entidad de la que hablamos y por iguales circunstancias tampoco podemos considerar la de Guadalmesí, a pesar de su facilidad para aguar en ella.

Sin embargo, el fondeadero de Getares sí reunía la capacidad de proporcionar protección a la flota de los cristianos - mientras no soplaran fuertes vientos de Levante-, al tiempo que no había obstáculo alguno para salir hacia Tarifa en caso de algún revés militar. La Ensenada de Getares, por añadidura, podía facilitar el agua dulce ${ }^{47}$ suficiente para atender las necesidades de las tripulaciones y está situada en un lugar idóneo para vigilar el triángulo portuario citado, aunque no era muy segura con fuertes vientos de Levante y por tal razón se abandonó la vez an-

${ }^{43}$ El almirante envió a uno de sus capitanes para decirle al rey de Castilla que no tenía más que 27 galeras y seis naves de apoyo.

44 Este detalle lo conocemos gracias a un documento contemporáneo a los acontecimientos. y en el que se nos dice que las galeras eran sólo 32. Véase en CODOIN. ACA. N 15.

45 Gran Crónica..., tomo II, p. 314

46 Según nos dice Pascual Madoz en su Diccionario geográfico, al hablar de las costas próximas a Algeciras - para lo que se apoya en el «Derrotero de las costas de España en el Mediterráneo» del brigadier de la Armada Tofiño de San Miguel—, el mejor fondeadero de la Bahía de Algeciras está junto a la desembocadura del río Palmones. También tenía fama de buen fondeadero el de Puente Mayorga.

47 Tengamos en cuenta de que en la misma desembocan dos cursos de agua que nacen en la cercana sierra: el Río Pícaro y el Arroyo del Lobo. 
terior para refugiarse en Tarifa. Así que, por todo lo dicho, abiertamente nos inclinamos por esta ensenada como el lugar elegido por el almirante de Castilla para que los hombres y naves de su flota «refrescaran» temporalmente sin abandonar la función de vigilancia que desempeñaban en el Estrecho.

De la importancia del fondeadero de Getares tenemos ya bastante información en las crónicas de Alfonso XI; y aunque esta información arranque en 1341, en los tiempos que mandaba la flota el almirante Egido Bocanegra y se preparaba el cerco castellano sobre Algeciras, no debemos menospreciar las ventajas de la estratégica posición de Getares con respecto a los puertos musulmanes del entorno, ya sea en aquellas fechas o en otros tiempos posteriores ${ }^{48}$. Para hacernos una idea de la misma no podemos olvidar que durante el cerco de Algeciras - ya en el mes de agosto de 1343, cuando parecía inminente un ataque de la flota musulmanael rey de Castilla llegó a ordenar al almirante Bocanegra que la mitad de las naves de guerra que allí tenía se situaran en la "entrada del puerto de Xetares a mejoría del viento" para frenar allí las naves que viniesen en socorro de la cercada plaza de Algeciras ${ }^{49}$.

Al hilo de cuanto precede, reiteramos que nos parece el fondeadero de Getares el lugar más adecuado para que naves y tripulaciones se fueran alternando sin abandonar la vigilancia del Estrecho. Y como hemos dicho, nos parece que fue a este fondeadero donde se movió el almirante Tenorio al recibir las seis galeras procedentes de Sevilla ${ }^{50}$ con la intención de combatir a la potente armada de Abu IHasan anclada en el puerto de Algeciras. En esta posición, dicen las crónicas ${ }^{51}$, estuvo tres días esperando que los musulmanes salieran a combatir, pero éstos no lo hicieron porque las condiciones - tácticas y meteorológicas- no les parecieron adecuadas.

Fue entonces cuando el almirante Alfonso Jofre Tenorio se vio en la necesidad de buscar un lugar con cierta protección donde sus hombre pudieran reponerse, porque mantenerlos embarcados y en tensión a lo largo de mucho tiempo significaba agotarlos antes del esperado enfrentamiento. $Y$ en ese lugar debía estar cuando en la mañana del sábado 8 de abril de 1340 amainaron los vientos y la mar se puso en calma. Estas condiciones fueron aprovechadas por los de Algeciras quienes «a gran priesa aguisaron la flota ... entraron los moros en ella ... e fueron se contra do estauan la flota de los christianos».

Hablan entonces las crónicas de la heroica actuación del almirante Jofre Tenorio al frente de la galera capitana antes de sucumbir; pero también nos cuentan de la prisa que se dieron los hombres de la flota castellana en escapar del lugar del

\footnotetext{
48 Será conveniente señalar al respecto que cuando los portugueses conquistaron Ceuta en 1415 su flota estuvo fondeada en Getares unos días antes del ataque definitivo a la ciudad.

49 Crónica, p. 371.

50 De allí también le trajeron noticias, proporcionadas por su esposa, de que a esas alturas había perdido la confianza del rey de Castilla a consecuencia de las habladurías que de él se hacían en la corte al no haber evitado el cruce de la flota musulmana.

51 Gran Crónica, tomo II, p. 316.
} 


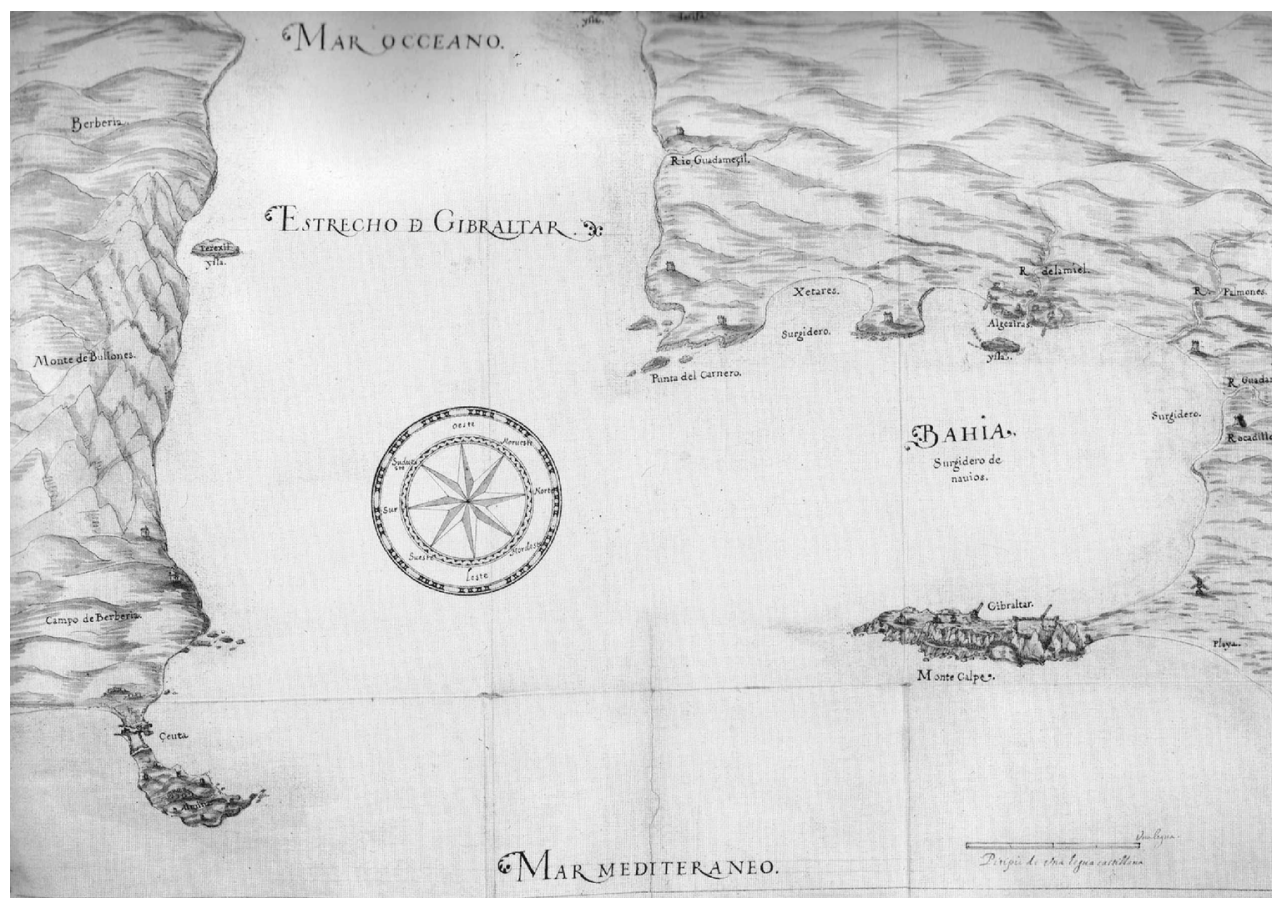

Mapa de la zona del Estrecho donde se puede apreciar la posición relativa entre los puertos de Algeciras, Ceuta y Gibraltar. También puede observarse la posición de la Ensenada de «Xetares" con respecto a los mismos.

enfrentamiento al ver caer el estandarte de su almirante. En ese momento todo el que pudo abandonó las galeras y se subieron a las naos ${ }^{52}$ de manera que, aprovechando el viento de Poniente que soplaba en aquellos momentos, abandonaron el Estrecho y navegaron rumbo a Cartagena dejando las galeras «desamparadas en el agua» con la excepción de cinco de ellas que a fuerza de remo llegaron a Tarifa ${ }^{53}$.

Así podíamos resumir el relato que nos hacen las crónicas de aquel desastre naval de 1340, pero afortunadamente encontramos más detalles sobre aquel enfrentamiento en un documento que se guarda en el Archivo de la Corona de Aragón ${ }^{54}$ y en el que Berenguer de Codinachs, oficial de Pedro IV de Aragón en el reino de Valencia, cuenta a este último las noticias que le proporcionaron algunos de los marineros que llegaron a Valencia a bordo de la única galera que escapó de las cuatro que tenían en el Estrecho. Este documento nos aporta unos detalles que forzosamente nos obligan a pensar en que la flota cristiana no estaba frente al

52 Las naves, naos, o «naus», era un tipo de embarcación que sólo se movían a vela y generalmente no se empleaban para el combate, sino para los transportes de apoyo logístico a las galeras.

53 Gran Crónica..., tomo II, p. 318.

${ }^{54}$ Se trata del ya citado CODOIN. ACA. N 15. 
puerto de Algeciras en la mañana del sábado 8 de abril de 1340, víspera del Domingo de Ramos. Y todo ello porque el documento tampoco dice exactamente dónde estaba la flota castellano-aragonesa cuando, inesperadamente, se presentó la flota musulmana procedente del puerto de Algeciras. Sin embargo, como el documento en cuestión precisa que la flota musulmana que salió de Algeciras estaba compuesta de 43 galeras y 35 leños armados, debemos pensar que una flota de esta envergadura no se pone en movimiento de buenas a primeras y que los marineros cristianos pudieron tener tiempo suficiente de reaccionar de haberlos tenido a la vista. En definitiva, nos resistimos a creer que de haber estado la flota cristiana frente al puerto de Algeciras no hubieran visto sus marineros la evolución de las embarcaciones musulmanas, además de no darles tiempo a tomar las mínimas medidas defensiva por mucha celeridad que pusieran los moros en salir del puerto de Algeciras y recorrer la distancia que los separaba de los castellano-aragoneses.

Porque según cuenta el informante a Pedro IV, las naves cristianas no pudieron enfrentarse en bloque a las que llegaban porque nadie había dispuesto que se trabaran entre sí para oponerse a las musulmanas, cosa que al parecer era lo más prudente en aquellos tiempos. Todo apunta, pues, que en el momento de la sorpresiva embestida de los musulmanes las naves cristianas estaban en una relativa situación de relajamiento y al estar aisladas las unas de las otras se vieron rodeados por todas partes ya que la flota del almirante Tenorio sólo contaba con 32 galeras y 19 naos ${ }^{55}$. Pero contaban además los marinos valencianos que, durante los tres días previos al sábado en que se dio el combate, el almirante dispuso la flota en orden de combate ${ }^{56}$ y que el sábado por la mañana no se hizo ya señal alguna de movilizar la flota. De aquí que la cristiana no estuviese preparada para el combate cuando llegó la de Algeciras que superaba ampliamente en naves y en hombres a la de los cristianos, sobre todo en el número de arqueros, pues las galeras de Algeciras venían preparadas hasta con tres castillos donde había 300 o 400 arqueros y ballesteros en cada una de ellas, mientras que las de Jofre Tenorio estaban escasamente armadas.

Contaba el informante en el documento, recogiendo cuanto decían los marineros aragoneses, que nada más iniciarse la pelea el hijo del almirante de Castilla, Garci Tenorio, abandonó el escenario rumbo a Tarifa con una galera ligera donde la tarde anterior había guardado los enseres más valiosos. Con respecto a Jofre Tenorio contaban que su galera había salido a pelear, pero que al ser rodeado por todas partes no sabían si había muerto o estaba preso. Y con respecto a esto, comentaban los marineros llegados a Valencia que al caer el estandarte del rey de Castilla los que peleaban en las galeras fueron a toda prisa hacia las naves a vela

55 Además de este detalle, se cuenta en el documento que ahora seguimos cómo las galeras aragonesas en el momento del ataque musulmán estaban en un extremo cuando se vieron envueltas por 6 galera en un costado y por 4 en el otro.

56 Según cuentan, se hizo esto a toque de añafil. El primer toque servía para que todos cogieran su armamento; el segundo para levar anclas y el tercero para que ocuparan sus lugares de combate. 
y escaparon del lugar rumbo a Cartagena donde llegaron 10 naves con un total de cinco o seis mil personas.

Al contrastar los datos de la crónica castellana con el documento aragonés, vemos que en lo fundamental no hay muchas diferencias entre ambas versiones con respecto al enfrentamientos ya que, por encima de todo, sale a relucir la falta de previsión del almirante de Castilla ante la proximidad de una flota superior en naves y en hombres. Quizá estuviese falsamente convencido de que los musulmanes no se atreverían a presentarle batalla en el lugar en que se encontraba, al igual que él no se había atrevido a atacarles en el puerto de Algeciras. Por ello seguimos pensando que la flota cristiana no debía estar frente a este puerto, sino fondeada en algún lugar cercano y desde el que no se veía el de Algeciras ya que de otra manera no se hubiera dado el ataque en las condiciones sorpresivas que se dio. Todo ello nos conduce una vez más a Getares, y de aquí nuestra hipótesis de que el desastre naval del que estamos hablando se produjo en ese fondeadero ya que la punta de San García se interpone entre Algeciras y el mismo Getares.

Así que, al hilo de lo que vamos viendo, es muy posible que el sábado 8 de abril de 1340 se observara desde las alturas que dominan Getares cierta relajación en la flota al mando del almirante de Castilla y que éste, como había hecho en días anteriores, no la disponía en orden de combate. Este detalle pudo resultar decisorio para que los de Algeciras se aprestara a salir con la flota lo más rápido posible y aprovechar el momento para sorprenderles con un contundente ataque que los dejó fuera de combate en poco tiempo y en el que los cristianos perdieron hombres y naves ${ }^{57}$ hasta el punto de que Castilla fue incapaz de rearmar otra flota para la zona hasta el mes de septiembre.

El rey de Castilla tuvo noticias del desastre naval de Getares a la media noche del mismo día en que se produjo, estando en Cabezas de San Juan ${ }^{58}$, por boca de Martín Fernández de Portocarrero, alcaide de Tarifa. Ante lo peligroso de la nueva situación, el rey envió a esta plaza a Alonso Fernández Coronel y dispuso también el rápido aprovisionamiento de la misma ante la previsible agresión. A continuación, inició una muy activa campaña diplomática para hacerse con las naves necesarias para dificultar los movimientos del sultán meriní en las aguas del Estrecho. Por ello no dudó en recurrir a su suegro, el rey Alfonso IV de Portugal, y lo mismo hizo con el rey de Aragón al que escribiría el día 14 de abril ${ }^{59}$ dándole cuenta del desastre naval de la semana anterior haciendo hincapié en el peligro que tal situación suponía para los dos reinos y pidiéndole ayuda naval, siempre apoyándo-

57 Debemos suponer, ya que en ningún momento se habla de naves hundidas, que los musulmanes capturaron 26 galeras y nueve naves. A la pérdida de estas naves hay que sumarle los prisioneros que hicieran en esta ocasión y de los cuales no podemos dar cifras, pero sí sabemos que unos y otros fueron llevados a Ceuta con gran deleite por parte del sultán y de la población según relata Gran Crónica..., tomo II, p. 320.

58 Gran Crónica..., tomo II, p. 320.

59 Publicado por Próspero de Bofarull en CODOIN. ACA., documento $\mathrm{n}^{\circ} 14$. 


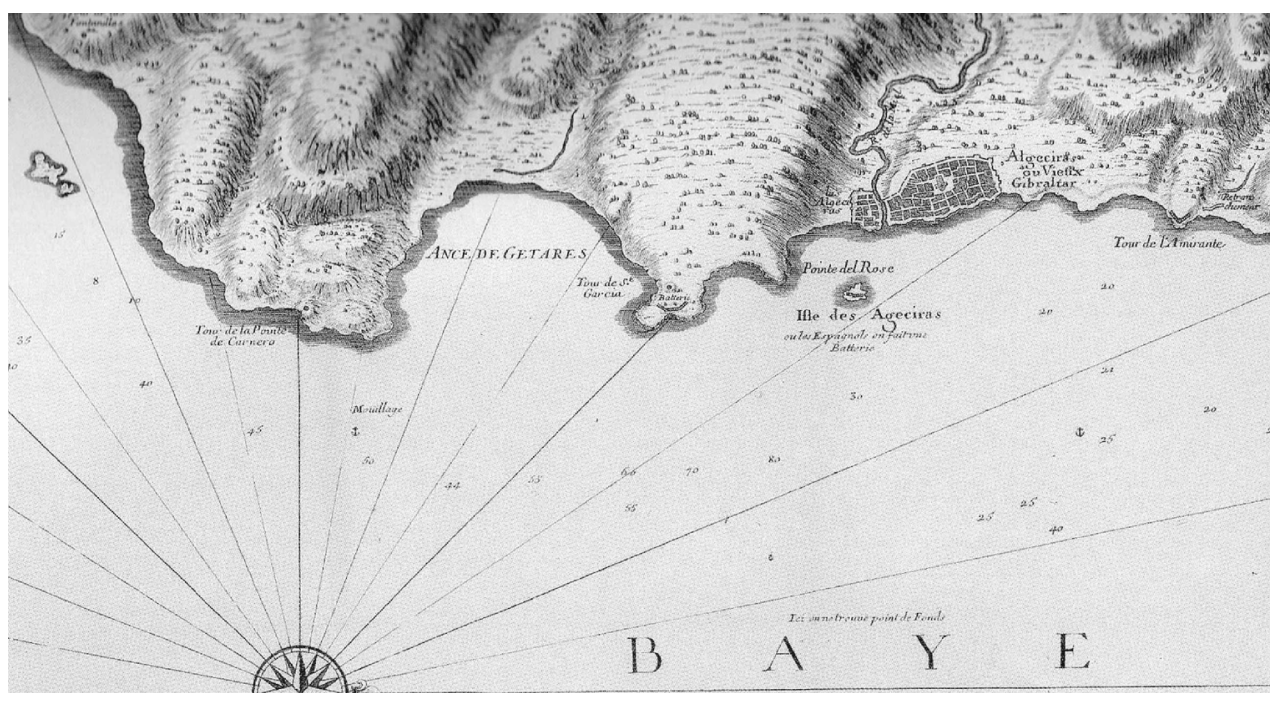

Apreciemos aquí con cierto detalle la posición de la Ensenada de Getares con respecto al puerto de Algeciras.

se en los tratados existentes entre ambos para las cuestiones marítimas. Pedro IV se dio por enterado y respondió el día dos de mayo desde Zaragoza diciendo que ayudaría a Castilla, pero apuntaba que en aquellos momentos no tenía los medios económicos necesarios para afrontar la construcción de una nueva flota. Los castellanos le adelantaron entonces el dinero necesario para construir y mantener 12 galeras durante tres meses ${ }^{60}$, motivo por el que ordenó la construcción de ocho galeras en Barcelona y cuatro más en Valencia.

Por lo que a Portugal se refiere no creemos que la ayuda llegara antes del mes de junio, pero lo sorprendente fue que las 15 galeras al mando del almirante Manuel Pezano se negaran a pasar de Cádiz ${ }^{61}$ por miedo a quedar desprotegidas las costas del Algarve, frente a un posible ataque musulmán. Esta circunstancia hizo que Alfonso XI buscara apoyo en Génova ${ }^{62}$ y todo apunta a que en aquel verano llegaron seis galeras genovesas al Estrecho, naves que habían de coincidir frente a Tarifa con las que se enviaron desde Aragón ${ }^{63}$ a finales de septiembre de 1340. Mientras tanto, también en Sevilla se preparaba una flota para enviar a las aguas del Estrecho lo antes posible ya que resultaba muy peligrosa la libertad de movimientos que allí gozaban las naves de Abu I-Hasan.

60 Gran Crónica..., tomo II, p. 325.

61 Ibidem..., p. 323

62 El 19 de junio. Esta fecha figura en la página 324 de Gran Crónica, como nota marginal.

63 Esto se deduce de una referencia indirecta que figura en los libros de cuentas que presentaron los aragoneses en 1341 para ajustar las cuentas entre Castilla y Aragón por la vigilancia del Estrecho. 
Éste aprovechó las ventajosas circunstancia y fue pasando desde Ceuta los pertrechos militares necesario para una gran ofensiva encabezada por el mismo sultán quien, en persona, cruzó de Ceuta a Algeciras el día cuatro de agosto ${ }^{64}$ y unos días más tarde se reunía con Yusuf I de Granada al objeto de preparar los detalles del cerco a Tarifa mientras celebraban la fiesta del nacimiento del Profeta ${ }^{65}$. Así que unos días después de este acontecimiento festivo para los musulmanes, concretamente el día veintitrés de septiembre, parece que se inició el cerco a esta plaza de manera que el sultán "... çercola toda saluo lo que esta entre la mar e la villa». Pero aquí también se colocó la vigilancia suficiente para evitar que nadie entrara ni saliera de la villa tarifeña por mar.

\section{LA PRESENCIA DE LAS FLOTAS DE CASTILLA Y ARAGÓN EN EL CERCO MERINI A TARIFA}

Para entonces, Alfonso de Castilla ya había enviado al frente de los defensores de la plaza a Juan Alfonso de Benavides, un hombre que respondió satisfactoriamente a la confianza depositada por su rey. Nada más iniciarse el cerco, y según cuentan las crónicas castellanas, los combates más duros se dieron en torno a la torre de don Juan y al postigo de Fatín, probablemente situados ambos en la muralla que rodea Tarifa por su lado de Levante ${ }^{66}$. No obstante, los defensores resistieron y a pesar del empeño puesto por los atacantes no consiguieron éstos entrar en la plaza, ni pudieron impedir que los sitiados informaran a Sevilla de la nueva y peligrosa situación. Cuando Alfonso XI tuvo noticias de lo que ocurría en Tarifa, envió a frey Alfonso Ortiz de Calderón —-por entonces prior del Hospital一, al frente de la flota que se había armado en Sevilla y que estaba compuesta de 15 galeras, 12 naos y cuatro leños ${ }^{67}$. Creemos que la intención inicial del rey de Castilla era, cuando se produjera el temido y esperado cerco a Tarifa, que operaran allí conjuntamente las flotas de Castilla y Aragón y que la presencia de ambas animara a los portugueses a sumarse al bloqueo del Estrecho para frenar el aprovisionamiento del ejército de Abu I-Hasan. Pero lo cierto fue que la flota aragonesa se retrasó más de lo esperado y todavía no estaba en el Estrecho cuando se inició el sitio a Tarifa ${ }^{68}$. Y sumado a lo anterior, los portugueses mantuvieron su inamovible postura cuando la flota al mando del prior del Hospital pasó frente a Cádiz con

64 Al-JATIB, Ibn: Historia de los reyes de la Alhambra.... p. 115.

655 de septiembre de 1340 según MANZANO RODRÍGUEZ: La intervención..., p. 256.

66 Aunque no participamos plenamente de la ubicación hasta ahora asignada a tal postigo, ésta es la opinión de SÁEZ RODRÍGUEZ, Ángel: Tarifa, llave y guarda de toda España. Fortificación y urbanismo. Instituto de Estudios Campogibraltareños. Algeciras, 2003, p. 91. Así lo cree también SEGURA GONZÁLEZ, Wenceslao: «La batalla del Salado», en Al-Qantir, n 3. Tarifa 2005, p. 19.

${ }_{67}$ Las galeras eran las naves de guerra por excelencia y estaban dotadas de remos y velas para su propulsión, así que podían moverse independientemente de la fuerza y dirección del viento. Las naos se empleaban fundamentalmente para el transporte y no tenían remos; los leños —una vez acondicionados-, venían a realizar las funciones propias de las galeras ligeras.

68 Ese día, 23 de septiembre, Pedro IV escribía a Alfonso XI diciéndole desde Barcelona que la flota aragonesa saldría en breve al mando del almirante Pedro de Moncada. 
dirección al Estrecho, a pesar de que éste llevaba cartas del rey de Castilla para el almirante de los portugueses rogando que acompañaran a la castellana en su misión. Por tal motivo la escuadra castellana continuó su viaje y se vio sola a la hora de afrontar el desbloqueo de Tarifa. Contrastando los datos que nos proporcionan las crónicas, posiblemente la flota castellana —reforzada por algunas naves genovesas- estuviera ya frente a las costas de la sitiada villa en los días finales del mes de septiembre o primeros de octubre. Sin embargo, para desgracia de los sitiados no estuvo allí más de una semana pues - transcurridos unos días-, se levantó un temporal con fuertes vientos de Poniente que arrastraron algunas naves castellanas hacia el Mediterráneo, mientras al resto las hizo embarrancar en las abruptas costa del Estrecho.

Apartándonos brevemente del desarrollo de los hechos en el Estrecho, debemos decir que este fenómeno meteorológico no fue una circunstancia local en la zona de la que estamos hablando puesto que el rey de Castilla - cuando fue a entrevistarse con su suegro a Jurumena (Portugal) para pedirle ayuda por tierra para descercar Tarifa-, se encontró que el río Guadiana bajaba muy crecido ${ }^{69}$ hasta el punto que no pudo cruzarlo teniendo que hacerlo el rey de Portugal y su hijo $^{70}$ en una barca. Mientras esto ocurría en las tierras del interior, el temporal hizo naufragar en aguas del Estrecho hasta nueve galeras y buena parte de las naos, que se perdieron el chocar contra las costas, razón por la que sus tripulantes fueron hechos prisioneros de los musulmanes ${ }^{71}$.

Después del naufragio de la flota castellana la situación volvió a ser favorable a los musulmanes ya que, las pocas naves que habían quedado en Algeciras, continuaron con su labor de aprovisionamiento por mar a los sitiadores. Decimos pocas naves, porque según las crónicas, el sultán había ordenado — con anterioridad a la llegada de la flota bajo el mando del prior del Hospital— que la mayoría de las embarcaciones empleadas en el transporte de efectivos desde África volvieran a sus puertos de origen ${ }^{72}$. Motivo por el que debemos suponer que ya se habían superado los tiempos por los cuales pidieron ayuda a otros reinos, o que al sultán de los benimerines no le preocupaba la ayuda naval que Castilla pudiera recibir de otras partes. Y en este sentido, lo que ocurrió fue que unos días más tarde, tal vez superado ya los días centrales del mes de octubre, la flota aragonesa hizo acto de presencia en las aguas del Estrecho. Desconocemos con certeza la fecha en que pudo ser avistada por sitiadores y sitiados, pero sí sabemos que el nuevo almirante

69 Parecen éstas las consecuencia del paso de un frente que afectó, al menos, a toda la parte occidental de la Península. El fenómeno tiene cierto paralelismo meteorológico con el que ocurrió en Trafalgar en 1805 al día siguiente de la trágica batalla naval.

70 Esta situación la recoge la Crónica en p.320 y la Gran Crónica en tomo II, p. 366.

71 Las tres galeras que no embarrancaron, entre las que se encontraba la del prior del Hospital, fueron a Cartagena y Valencia, por lo que podemos hacernos una ligera idea de la fuerza de los vientos de aquella tempestad otoñal.

72 Sólo 12 galeras habían quedado en Algeciras. En tal situación a la llegada de la flota castellana comenzó a preocupar a los sitiadores el aprovisionamiento por mar ya que las embarcaciones más pequeñas de los musulmanes «... que les trayan vianda no ossauan andar por miedo de los leños». 
aragonés, Pedro de Moncada ${ }^{73}$ había salido con la flota de Barcelona el 27 de septiembre y también que pasó por Valencia para recoger al resto de las galeras. Pero incluso emprendiendo rumbo a las Baleares ${ }^{74}$ antes de llegar a Tarifa es muy probable que pasados los días centrales de octubre estuvieran frente a esta villa porque los marinos aragoneses disponían oficialmente de una media de quince días para llegar de sus puertos de partida hasta el Estrecho. Así que aun sin apresurase por llegar a la zona de conflicto, parece lógico que lo hicieran sobre la fecha indicada y mucho más cuando conocemos, según nos hace saber la Crónica de Alfonso XI y la Gran Crónica, que llegó al Puerto de Santa María entre los días 22 y 24 de octubre ${ }^{75}$. Para esas fechas, los reyes de Castilla y Portugal ${ }^{76} \mathrm{con}$ sus respectivos ejércitos estaban acampados en la margen izquierda del río Guadalete, cerca de Jerez, con la intención de llegar hasta Tarifa para liberarla del cerco a que la tenían sometida meriníes y granadinos.

Así que, si en las fechas indicadas, las crónicas recogen la llegada del almirante del reino de Aragón al campamento de los reyes cristianos, tal vez un día antes, o como máximo dos, había cruzado con su flota frente a la sitiada Tarifa y ya podemos imaginarnos la sorpresa del almirante Pedro de Moncada al no encontrar allí ni una sola nave de las que esperaba encontrar, pues en las instrucciones que traía del rey de Aragón se decía claramente que en el Estrecho debía «mezclarse» - cita textual-, con los almirantes de Castilla y de Portugal. Ante la inesperada situación cabe pensar que la flota aragonesa pasara de largo por el Estrecho y se dirigiera hacia el Oeste buscando las galeras castellanas o portuguesas. Sin duda, encontró a esta últimas en las proximidades de Cádiz y lo más razonable es que le

73 Este hombre fue nombrado almirante de la flota aragonesa el día seis de mayo de 1340 en sustitución de Gilabert de Cruilles, el almirante que murió en la cercanías de Algeciras a finales del mes de septiembre del año anterior, tal y como expusimos páginas atrás.

${ }_{74}$ Pedro de Moncada debía ser bastante joven cuando fue nombrado para el cargo y la flota que traía al Estrecho estaba compuesta de 12 galeras y un leño de cien remos, naves en las que se había invertido mucho esfuerzo y dinero. Por tal razón, las instrucciones que traía el almirante del rey de Aragón eran bastantes restrictivas en lo que se refería al empleo de la flota y modo de actuar del almirante. Por esa razón no creemos que Pedro de Moncada tomara el rumbo más directo hacia el Estrecho, lo más probable es que una vez reunida la flota tomara el rumbo de las Baleares para preparar a sus hombres antes de que éstos se vieran envueltos en una situación de guerra.

75 No podemos precisar la fecha con exactitud ya que esta noticia la extraemos de Crónica, p. 323 y de Gran Crónica, tomo II, p. 390; allí se dice que mientras estaba el rey en el campamento de la orilla sur del Guadalete, cerca de Jerez, llegó allí la flota aragonesa. Las fechas de acampada en la margen izquierda del Guadalete se deduce de la del enfrentamiento del Salado y retrocediendo hasta encontrar los días que estuvieron acampados en las proximidades del citado río.

76 Alfonso XI había pedido ayuda al rey de Portugal a través de su esposa, la reina doña María, quien se puso en marcha hacia Portugal nada más saberse en Sevilla las noticias de que había comenzado el cerco a Tarifa. Cuando conoció la intenciones de su padre envió aviso al rey de Castilla para que éste fuese a Portugal a negociar con el monarca portugués. Debían transcurrir entonces los últimos días de septiembre o primeros de octubre y a marchas forzadas emprendió el camino hacia Jurumena, allí no pudo cruzar el Guadiana enviado aviso al rey de Portugal quién, acompañado de su hijo, pasó en una barca para entrevistarse con el rey castellano. No se llegó a un acuerdo en la primera entrevista, pero sí al día siguiente y entonces el rey de Castilla emprendió el camino de regreso a Sevilla. Fue a la vuelta de este viaje cuando Alfonso XI tuvo conocimiento de la perdida de su flota en aguas del Estrecho. Unos días después llegó a Sevilla el rey de Portugal y a mediados de octubre se puso en marcha el ejército hacia Tarifa. 
informaran de las órdenes que tenían de no alejarse de allí. Ante el cúmulo de circunstancias adversas, que para nada se contemplaban en las instrucciones que había recibido de su rey, el almirante aragonés tomó la decisión de contactar con el rey de Castilla quien era el destinatario final de aquellas cartas que traía y en las que figuraban los términos en los que había de colaborar con los almirantes de Castilla y Portugal. De aquí que emprendiera rumbo hacia el Puerto de Santa María y sabiendo allí que el rey de Castilla estaba acampado en las proximidades de Jerez, utilizando el leño armado que traía, se presentó en el campamento del Guadalete. Y no terminaron aquí sus sorpresas puesto que Alfonso XI le pidió que se dirigiera sólo con su flota al Estrecho sin contar con la colaboración de las naves portuguesa ya que éstas, después de estar navegando desde el mes de junio, debían emprender el camino de regreso a Portugal.

Pero retomando los sucesos en Tarifa, cuando vieron allí por primera vez la flota de Aragón, diremos que pudieron repetirse las sensaciones experimentadas por sitiadores y sitiados cuando llegaron a la zona las naves de la flota al mando del prior del Hospital, unos veinte días antes. Pero los sitiadores tenían ahora en sus manos una baza a su favor que intentaron aprovechar; ésta no era otra que la cautividad de los marineros de la flota castellana y como medida de presión amenazaron con decapitarlos a todos si los de Tarifa no se rendían. La respuesta de los sitiados, en previsión de lo que pudiera ocurrir, fue disparar contra todos los que se acercaban a las murallas y los musulmanes replicaron con el más «afincado combatimiento" de cuantos se habían realizado hasta entonces. Los sitiados se mantuvieron firmes a pesar de que las naves de Argón se alejaron del Estrecho sin intervenir para nada; no obstante, aquello era la señal inequívoca de que algo se estaba moviendo fuera de su entorno inmediato. Y probablemente también en el más cercano, pues las naves de la flota castellana que habían escapado del temporal debían estar regresando a las proximidades de Tarifa; con respecto a esto, las crónicas dicen bien claro que las naves al mando del prior del Hospital ya estaban allí con anterioridad al día en que se produjo el enfrentamiento del Salado.

Y lo mismo se dice en estas fuentes con respecto a las naves del reino de Aragón, las cuales pudieron regresar a las inmediaciones de Tarifa el día 25 o 26 de octubre, como muy tarde, pues no más de un día duraría el viaje desde el Puerto de Santa María después de que el rey de Castilla le pidiera que regresara a las proximidades de Tarifa. De hecho, el 29 de octubre, cuando el ejército castellanoportugués llegaba por tierra a las inmediaciones de la Ensenada de Valdevaqueros, la crónica de Alfonso XI hace alusión a la presencia de la flota aragonesa en aquellas aguas y dice también que el almirante de Aragón no quiso sumarse al desembarco que efectuaron algunos hombres de la flota de Castilla para intervenir en tierra el día de la batalla. En opinión de Jerónimo de Zurita, tal vez con mucha razón, la decisión del almirante Pedro de Moncada estaba influenciada por la suerte que corrió el almirante Gilabert de Cruilles al desembarcar en las proximidades de Algeciras un año antes. Posiblemente pesara más en su ánimo las órdenes de su rey que los deseos de colaborar en tierra con los castellanos; o quizá no estuviera 
muy seguro del resultado final de aquel combate en el que el ejército cristiano no contaba con las condiciones más favorables. Lo cierto es, al decir del cronista, que no sólo se negó a que sus hombres participaran por tierra en la batalla, lo más llamativo es que - una vez derrotado el ejército musulmán - tampoco quisiera intervenir en el mar cuando el rey de Castilla le pidió que cortara la retirada de Abu IHasan hacia Ceuta.

\section{LA VICTORIA DEL SALADO 77}

Sin ánimos de entrar en detalles con respecto al itinerario, porque ya lo hemos hecho en otro artículo ${ }^{78}$, hemos de decir que el ejército castellano-portugués salió de Sevilla el día 16 de octubre y ya vimos páginas atrás que habían asentado su campamento en la orilla izquierda de río Guadalete el día 22 del mismo mes. Desde allí continuó la marcha y, pasando por el puerto de Facinas, llegó a las proximidades de la Ensenada de Valdevaqueros el domingo día 29 a eso de mediodía. La vanguardia del ejército, en la que figuraba el concejo de Sevilla, acampó en las inmediaciones de la Peña del Ciervo taponando la abertura orográfica existente entre la citada peña y el mar —no más de 500 metros-, para proporcionar seguridad al resto del ejército que acampó en las vegas del Río del Valle, protegido por las alturas de la sierras de Enmedio y de Saladaviciosa.

Así que hasta la Peña del Ciervo hubo de llegarse aquella tarde el rey de Castilla para ver la ubicación de los musulmanes en las colinas que dominaban el curso del arroyo del Salado después de haber levantado el cerco a Tarifa y tomado posiciones en aquellas alturas. Para facilitar la aproximación de su ejército al campo de batalla, ordenó don Alfonso que se allanaran las trincheras que habían abierto los musulmanes en la zona de la Peña ${ }^{79}$ volviendo luego al campamento principal para reunirse con el rey de Portugal, y con los hombres de sus consejos, para determinar la disposición más conveniente en el decisivo combate que estaban dispuestos a afrontar al día siguiente. En este consejo, contando con los efectivos que llevaban ${ }^{80}$ y considerando que sus rivales le triplicaban en número y estaban mejor posicionados ${ }^{81}$, se acordó que el rey de Portugal ${ }^{82}$ fuese por la

77 Este apartado viene a ser un resumen de nuestro trabajo: «La batalla del Salado sobre la toponimia actual de Tarifa», en Aljaranda, $\mathrm{n}^{\circ} 67$. Tarifa, 2007.

78 «Los itinerarios de Alfonso XI desde Sevilla al Campo de Gibraltar en sus campañas del Estrecho», en Historia, Instituciones, Documentos, $\mathrm{n}^{\circ} 33$ (2007), pp. 309-327.

79 Según las crónicas castellanas, aquella zanja se abrió por orden del sultán al llegar las naves de la flota que mandaba el prior de la Orden del Hospital. El arzobispo de Toledo también se hace eco del "atrincheramiento» existente en aquel lugar. Véase en BENEYTO PÉREZ, Juan: El cardenal Albornoz,canciller de Castilla y caudillo de Italia. Espasa Calpe. Madrid, 1950, 330.

80 Según la Crónica, p.322, en el alarde que hicieron antes de salir de Sevilla encontraron que llevaban 8.000 hombres de a caballo y 12.000 de a pie. También dice la Crónica que durante el camino se le unió más gente, aunque no dice cuantos.

81 Tengamos en cuenta que, además de tenerlos al alcance de sus ojos, hubo un desertor entre los musulmanes que les informó de cómo estaban desplegados éstos y de cuántos eran sus efectivos. Gran Crónica, tomo II, p. 409

${ }^{82}$ Con el rey de Portugal llegaron unos mil hombres de a caballos. Por eso el rey de Castilla reforzó estos efectivos con otros tres mil más, pertenecientes a las órdenes militares. 
parte más cercana a la sierra y se enfrentara al rey de Granada, mientras el rey de Castilla, con el grueso del ejército ${ }^{83}$ formando la vanguardia y el ala derecha, avanzaría por la llanada próxima a la costa para enfrentarse al sultán de los benimerines. Pero cuando todo estaba aparentemente decidido, aconsejó don Juan Manuel que aquella noche se enviara un contingente por tierra a Tarifa con la finalidad de que a la mañana siguiente, junto a las tropas que habían sufrido el asedio y los de la flota, pudieran atacar por retaguardia a las tropas de Abu I-Hasan de manera que éste se viera obligado a distraer algunos efectivos de la zona por donde atacaría Alfonso XI. Aceptado el plan, el rey de Castilla no modificó el planteamiento general del despliegue, pero hubo de transferir algunas fuerzas al núcleo que se desplazaría a Tarifa ${ }^{84}$ sustrayéndolas de las que inicialmente se había pensado que habían de acompañarle al día siguiente.

En la mañana del lunes día 30 de octubre los cristianos se pusieron en marcha nada más salir el sol, siguiendo un itinerario que les debía apartar de la costa para cruzar el curso del Río Jara por lugares que no supusieran peligro para los hombres de a pie y menos para la pesada caballería cristiana. Por ello suponemos que debieron cruzar el citado río por vados donde hoy se encuentra el molino del Mastral y después bajar por el camino que desde Puertollano lleva hasta Tarifa. Una vez cruzado el Río Jara se debió adoptar el orden de batalla planeado en la tarde anterior, y hasta es posible que en estas evoluciones se retrasaran un poco porque el sol debía estar todavía muy bajo a esas horas, circunstancia ésta que les dificultaba la visión y se convertía en un elemento adverso a la hora de la batalla ${ }^{85}$ Cuando avanzaron de nuevo hacia el Salado se adelantó la vanguardia; estaba formada ésta por el núcleo central del despliegue y en la misma se incluyeron, entre otros muchos señores, a don Juan Manuel, a don Juan Núñez de Lara y al maestre de la Orden de Santiago, con sus respectivas mesnadas. Retrasando un poco el paso, en el ala derecha del despliegue se situó el rey de Castilla con gente próxima a los de su casa, y situó a su retaguardia a Gonzalo de Aguilar con el concejo de Córdoba. Por su parte, el rey de Portugal con las mesnadas de su reino y el grueso de los efectivos de las órdenes militares - ya hemos dicho que la de Santiago iba en la vanguardia-, se situó a la izquierda del despliegue. La caballería cristiana llevaría el peso de la batalla durante los primeros momentos, así que el rey de Castilla ordenó que la mayor parte de los hombres de a pie ${ }^{86}$ fuesen bajo el mando de Pedro Núñez de Guzmán disponiendo que éste constituyera la reta-

${ }^{83}$ El total de la caballería del rey de Castilla, que constituían la vanguardia y el ala derecha, ascendería a unos 8.000 hombres. Con respecto a la gente de a pie es muy arriesgado dar cifras para los que se integraban en aquel cuerpo de ejército. Sabemos que el total de los infantes llegaba a unos 13.000 hombres, pero la mayor parte de ellos quedaron al mando de Pedro Núñez de Guzmán formando la retaguardia, o bien guardando el campamento.

${ }_{84}$ Aquella gente pasó de noche y, según relatan las crónicas, se sumaron a los defensores de Tarifa unos 1.000 hombres a caballo y 4.000 de a pie.

${ }^{85}$ Este detalle se recoge en la Gran Crónica. Pero Wenceslao SEGURA GONZÁLEZ lo trata con más detalle y amplitud en su artículo: "La batalla del Salado», en Tarifa en la Edad Media. EXCMO. Ayuntamiento de Tarifa. Tarifa, 2005, p. 187.

${ }_{86}$ Ya hemos apuntado que buena parte de éstos, sin que podamos decir cuántos, se quedaron defendiendo el campamento. 
guardia del despliegue, pero en una posición no muy alejada del monarca por si llegaba a necesitarlo.

Pero antes de continuar con los detalles propios de la evolución de la batalla ${ }^{87}$, en atención a los lectores que no conozcan la topografía de Tarifa, debemos anticipar que geográficamente hablando el Salado no es más que un arroyo de unos seis kilómetros de longitud ${ }^{88}$ y de cuyo curso sólo nos interesa ahora el tramo que discurre desde las proximidades del Puerto de Piedracana ${ }^{89}$ hasta el mar, porque fue en este tramo - entre la playa y los primeros escarpes serranos- donde se produjo el enfrentamiento que tratamos. Aquí el Salado corre en dirección EsteOeste en la parte más alta para luego, al encontrarse con la loma de Los Prados describir una curva y correr definitivamente hacia el Suroeste. Después de esta curva se suaviza la pendiente de dicho arroyo y todavía lo hace más a partir del Cortijo del Brocón, donde se produce un ensanche del valle cuando el Salado recibe a otro arroyuelo que baja del Bujeo de la Breña, todo esto a unos tres kilómetros de su confluencia con el Río Jara, del cual es tributario el Salado. Al dejar el valle donde se asienta hoy el Cortijo del Brocón, el curso del Salado se encajona de nuevo, pero un poco más abajo, a unos dos mil quinientos metros de su confluencia con el Río Jara, el arroyo que seguimos discurre por un valle que se ensancha constantemente y forma una llanada que se extiende hasta la playa y que, por su derecha, enlaza con la amplia vega que se forma en la margen izquierda del Jara. Ya al final del curso del Salado, y por lo que a su margen izquierda se refiere, existe una estrecha llanura que, entre la loma de El Pinganillo y el mar, pone en comunicación las cuencas del Río de la Vega y la de el tantas veces mencionado arroyo del Salado.

Con lo anterior hemos intentado dejar más o menos claro que la margen derecha del arroyo en cuestión es bastante llana, pero no ocurre lo mismo con las tierras situadas en su margen izquierda. Aquí el relieve es mucho más accidentado ya que, subiendo desde el mar hacia la sierra, las lomas de El Pinganillo, la de Las Peñuelas y El Polear, se elevan unos 60 metros por encima del curso del Salado, para llegar a los 80 en Cerro Palomino y todavía más si nos situamos sobre el Bujeo de la Breña o sobre el Cerro del Tesoro ya que la cota de estos dos cabezos alcanzan respectivamente los 258 y 288 metros sobre el nivel del mar. Pero estas alturas predominantes no está inmediatas al Salado, sino que se sitúan a más de dos kilómetros del mismo, apareciendo entre el curso del arroyo y estas elevaciones otros cabezos —como El Novillero y Los Zorrillos-, que con sus 160 y 180 metros de promedio respectivamente forman una especie de escalón por el que se

${ }^{87}$ Aunque los preparativos se iniciaron muy de mañana, el enfrentamiento propiamente dicho debió comenzar a media mañana aproximadamente; la razón fue que debieron esperar a que el sol se elevara sobre el horizonte para que no le molestara, al tenerlo los musulmanes de espalda.

88 El Salado nace en los Tajos del Sol, a 350 metros de altura aproximadamente.

89 El citado puerto pone en contacto, o separa, las cuencas altas del Salado y del Río de la Vega. Todas la referencias topográficas las damos siguiendo el mapa que sirve de base a la figura que se adjunta en este apartado. Corresponde al mapa del Instituto Geográfico Nacional, hoja 3-2, escala 1: 25.000. Edición de 1989. 
sube con cierta facilidad a las alturas superiores si utilizamos una vaguada en la que se ubica el Cortijo de Ruedalabola ${ }^{90}$ y por la que se alcanza una antigua explotación minera muy cerca ya de Los Zorrillos.

Pues bien, para nosotros resultan fundamentales los hechos acontecidos en las inmediaciones de esta vaguada ya que en lo alto de la misma -en el escalón intermedio que forman los cabezos últimamente citados y en los collados próximosse asentaba el real del sultán de los benimerines. Indiscutiblemente, fueron aquellas pendientes de la margen izquierda del Salado — desde la misma playa al Bujeo de la Breña - las que ocuparon los benimerines y granadinos —estos últimos más hacia la sierra según todas las fuentes ${ }^{91}$ - para desplegar sus efectivos. A juzgar por el saqueo que los cristianos llevaron a efecto en el mismo real de los meriníes durante la batalla y después de ésta ${ }^{92}$, además de tener en cuenta el significativo nombre de «Cerro del Tesoro» que aún guarda este topónimo tarifeño, podemos descartar cualquier duda y asegurar que fue éste el lugar elegido por Abu I-Hasan para asentar su campamento, mientras que el rey de Granada no pudo asentar en otro cabezo más que en el hoy conocido en Tarifa como Bujeo de la Breña, situado ligeramente hacia la sierra y cubriendo los caminos que desde la Peña del Ciervo llevan hasta el Puerto de Piedracana. Y dado que los granadinos eran menor en número, debemos suponemos que la zona de unión, o de solapamiento quizá, entre los dos ejércitos musulmanes debía estar situada en las pendientes que descienden de El Novillero hasta el Salado. Todo ello teniendo en cuenta lo que luego ocurrió y que expondremos un poco más tarde.

Ahora, después de vistos los despliegues de musulmanes y cristianos, incidiremos en que a todas luces los musulmanes ocupaban un terreno más ventajoso y que al menos le duplicaban o triplicaban ${ }^{93}$ en número a los cristianos - no por otra razón adoptó la caballería de éstos la formación en tropeles ${ }^{94}$ frente a un enemigo que formaba en líneas escalonadas en profundidad-. No obstante, ni lo uno ni lo otro fue obstáculo para que el ejército cristiano derrotara en un corto espacio de tiempo al nutrido ejército musulmán. Adelantado lo anterior, existen razones más que justificadas para preguntarse qué pudo pasar en aquellas pocas horas y cómo se llegó a poner en franca desbandada a un ejército tan numeroso como aquel que había traído el sultán

90 Este cortijo, que no se encuentra el mapa que adjuntamos, está situado a una cota aproximada de 70 metros.

91 Según nos dicen todas las fuentes consultadas, el sultán situó su real en un otero alto y alejado de la villa, al tiempo que el rey de Granada escogió para asentar otro cabezo situado más hacia la sierra.

92 Sea como fuere, en lo que sí insisten las crónicas es en que muchos de los vencedores aprovecharon la ocasión para subir al real de los musulmanes y quedarse con mucho de lo que allí encontraron. De hecho, el rey de Castilla tuvo dificultades para recuperar el total del botín ya que muchos huyeron con lo personalmente obtenido a otros reinos.

93 Las crónicas castellanas parecen exagerar a la hora de cuantificar a los musulmanes, pero en el pero de los casos los efectivos de éstos podían llegar a los 60.000 hombres. Para más detalles Véase HUICI MIRANDA, Ambrosio: Las grandes batallas de la reconquista durante las invasiones africanas. Instituto de Estudios Africanos. Madrid, 1956, pp. 367-371.

94 Según dice la Segunda Partida, los tropeles se utilizaban cuando no había suficientes efectivos como para formar líneas. En este caso el rey de Castilla aconsejaba llevar los caballos muy juntos para facilitar la capacidad de penetración del tropel en las filas contrarias. 
de los benimerines y al que se había sumado el de los granadinos. Desde luego, una de las acertadas maniobras fue desplazar parte de los hombres a Tarifa, pero aquello hubiera resultado insuficiente de no producirse el deslizamiento de los granadinos hacia la sierra dejando un hueco por el que penetró hasta el real benimerí, sin oposición apenas, el ala izquierda de la vanguardia cristiana constituida por los efectivos de don Juan Núñez de Lara y los de la Orden de Santiago al mando éstos de su maestre, don Alonso Méndez de Guzmán.

Para entender cómo se llegó a esta situación debemos conocer lo que simultáneamente estaba sucediendo en las diferentes partes del campo de batalla, e incluso lo que se movía entre éste y Tarifa, o sea, en el valle del Río de la Vega. Sin esta conjunción de circunstancia, producidas todas ellas en lugares relativamente apartados de donde combatía el grueso de los dos ejércitos ${ }^{95}$, hubiera sido imposible sembrar el desconcierto final que se produjo entre los musulmanes, causa indiscutible de su huída final hacia Algeciras. Pero no creamos que todo le fue bien a los cristianos; según dicen las crónicas, en los momentos iniciales del choque su vanguardia se quedó frenada nada más llegar al Salado ${ }^{96}$ y lo mismo le ocurrió al ala derecha a pesar de que fue allí donde se produjeron los primeros enfrentamientos con suerte dispar. Y si allí no les fue bien en los primeros compases, peor les fue a los del ala izquierda después de un asalto inicial sobre las posiciones granadinas que ocupaban aquellas lomas que desde el Salado suben hacia el Bujeo de la Breña, a la altura de el Cortijo del Brocón. Según parece, el primer contraataque de los granadinos estaba a punto de echar por tierra el empuje de aquellas fuerzas cuando vino en su ayuda la infantería del rey de Castilla ${ }^{97}$. Tal vez como consecuencia del empuje de la infantería, o quizá porque las condiciones del terreno se hacían más favorables hacia el camino que sube al Puerto de Piedracana, el caso es que se produjo un desplazamiento del combate hacia el lado de la sierra. Tal circunstancia la recoge una fuente portuguesa ${ }^{98}$ y no es extraño que se produjera tal efecto como consecuencia de la pretensión de los cristianos por envolver a los granadinos y la de éstos por evitar tal maniobra. Sin embargo, aquella situación trajo como consecuencia indirecta que los efectivos granadinos se desconectaran de los benimerines cuando los tropeles de la Orden de Santiago ${ }^{99}$ y de

95 Nada decisivo se produjo en la zona por donde el ejército castellano realizó el esfuerzo principal, esto es, por donde combatía el rey de Castilla. De aquí que los movimientos ejecutados en otras partes resulten ligeramente confusos cuando se leen las crónicas que, naturalmente, se centran en la actuación del monarca.

96 Don Juan Manuel no se atreve a avanzar y entonces las fuerzas del ala derecha -las que iban bajo el mando directo del rey de Castilla-, llegan también al curso del Salado iniciándose allí los primeros combates.

97 Según podemos leer en HUICI MIRANDA: Las grandes batallas de la reconquista..., p. 359, el historiador Ibn al-Jatib, que participó personalmente en la batalla, dice que los granadinos estaban a punto de vencer a los que mandaba el rey de Portugal cuando vinieron en su ayuda unas fuerzas situadas entre los dos reyes cristianos que le procuraron el triunfo al de Portugal.

98 «Portugalie Monumenta Histórica, Scriptores», volumen I. Citado por HUICI MIRANDA en las pp. 381-383 de la obra de la nota anterior.

99 Precisamente, al tratar de hacer un trabajo sobre la intervención de la Orden de Santiago en esta batalla fue cuando nos dimos cuenta de ciertos detalles que nos obligaron a pisar el terreno donde se dio el combate y responder así a ciertas dudas que no resolvían las crónicas. 


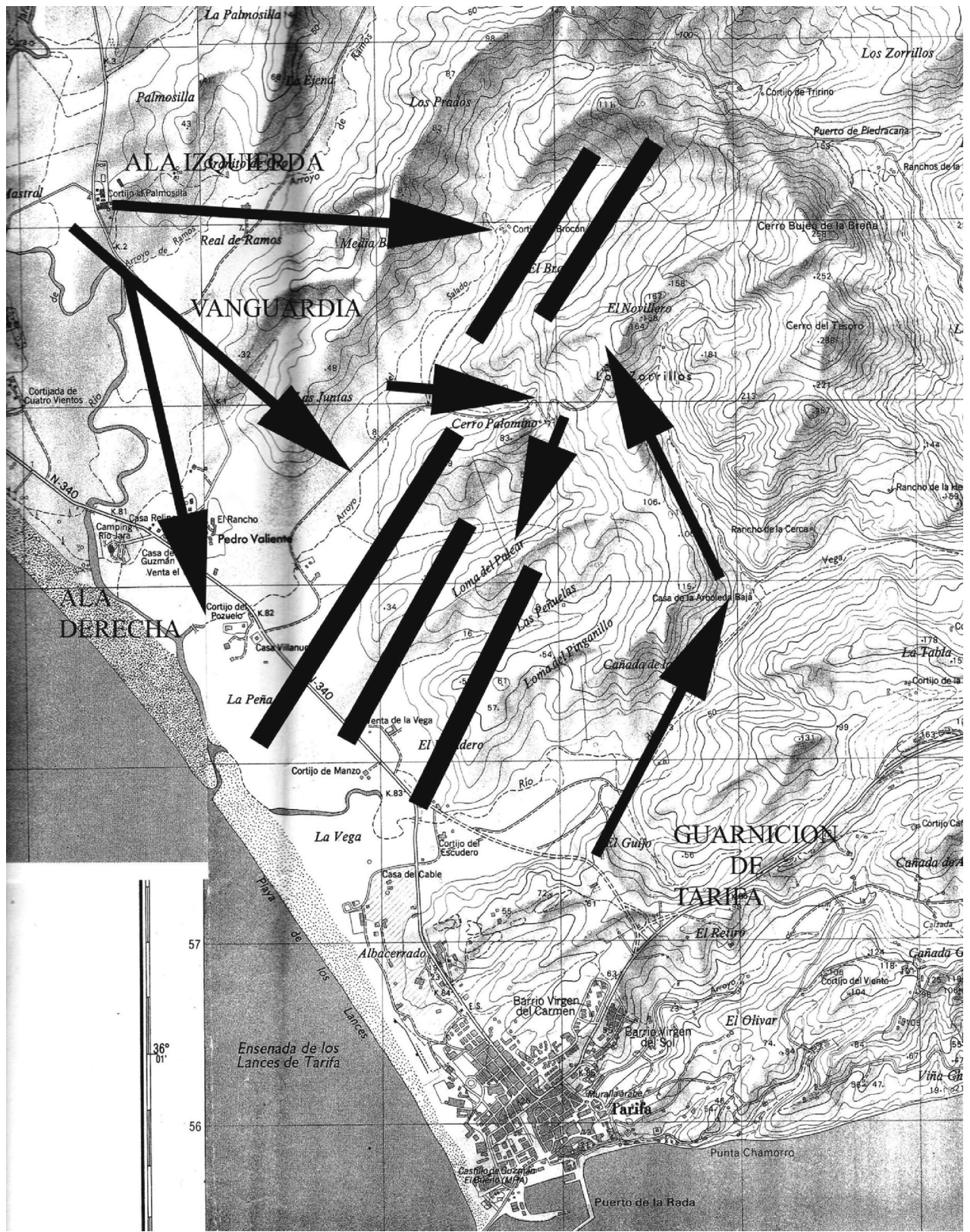

Señalamos con flechas el despliegue y movimientos del ejército cristiano. El despliegue de los musulmanes queda representado por barras. 
don Juan Núñez pasaban finalmente el Salado y subían por la vaguada —o por las suaves pendientes de las inmediaciones de ésta hacia el lado de la sierra- hasta la zona El Novillero-Los Zorrillos que era la zona donde estaba el real de Abú I-Ha$\operatorname{san}^{100}$.

Los cristianos no llegaron al campamento en el primer impulso ya que inicialmente parece que se desviaron a su derecha según avanzaban; fue luego, al ver los más retrasados del tropel que el real musulmán estaba tan cerca, cuando la gente que peleaba en la vanguardia de aquel tropel cambió de dirección y subió, sin la suficiente oposición, hasta el campamento de los benimerines. Pero si la fácil penetración de los cristianos en las filas musulmanas la explicamos por el desplazamiento de los granadinos hacia su derecha, cómo explicar el que los cristianos llegaran al real benimerí casi en un paseo cuando sabemos que allí había dejado Abu I-Hasan un total de 3.000 hombres de a caballo y 8.000 peones ${ }^{101}$. A tenor de las cifras que manejamos y de la importancia del campamento, no resulta llamativo el número de hombres que defendían el real; lo que sí debemos preguntarnos ahora es dónde podían estar la mayor parte de estos efectivos en el momento que se produjo el ataque de este tropel desde el Salado. Para nosotros sólo cabe una explicación; ésta nos es otra que el grueso de aquellos efectivos musulmanes que guardaban el campamento bajaron por la vaguada que lleva hasta el curso del Río de la Vega para atajar el ataque proveniente de Tarifa.

Porque la gente que la noche anterior había llegado hasta la villa, junto con los que habían estado sitiados y la gente de la flota castellana, aprovecharon los primeros compases del enfrentamiento para salir de la protección de las murallas y situarse en El Guijo ${ }^{102}$ formando un grupo que podía superar los 6.000 hombres con más de mil de ellos a caballo. No era aquella caballería suficiente para actuar con eficacia frente a la más numerosa de los musulmanes, así que debieron fijar como objetivo un lugar más distante, pero en el que no hubiera tanta caballería. No fue otra la razón por la que se dirigieron directamente al real de los musulmanes que se ubicaba en la zona Novillero-Zorrillos y la alcanzaron después de superar la distancia que los separaba - unos tres kilómetros- apoyándose en la ventaja que los musulmanes atendían a lo que les llegaba por el Salado y en que les resultaba difícil bajar a caballo por las escarpadas pendientes existentes hacia el Río de la Vega para cortarles el avance. Los que podían hacerlo con más garantías de éxito eran los que custodiaban el real y, lo más razonable, es que parte de ellos bajaran por la vaguada que se une al Río de la Vega a la altura de Casa de la Arboleda Baja. Vaguada que, junto al resto del camino seguido por los de Tarifa, debió ser desbrozada en los días inmediatamente anteriores al combate para facilitar el transporte de la impedimenta propia del real musulmán, desde su asentamiento en las inmediaciones de Tarifa, hasta la zona Novillero-Zorrillos.

100 Las crónicas dicen que llegaron al mismo alfaneque del sultán. Crónica p. 326, y Gran Crónica, tomo II, p.428.

101 Crónica, p. 326 y Gran Crónica, tomo II, p. 429.

102 Así en el mapa que acompañamos. Se llama también Loma de las Canteras. 
Pero volviendo a las consecuencias que tuvo aquella salida de los hombres de Tarifa, diremos que después de derrotar a los musulmanes que bajaron a frenarlos, alcanzaron el real de éstos y en aquella zona se reunieron con los santiaguistas y con los de don Juan Núñez ${ }^{103}$. Formarían ya un grupo que bien podía superar los 7.000 hombres, de los que un tercio de ellos combatirían a caballo, así que sin miedo a ser hostigados por la espalda -no olvidemos que los granadinos estaban siendo derrotados hacia la sierra-, se volvieron hacia el grueso de las fuerzas benimerines que en cotas más bajas impedían al paso a las huestes del rey de Castilla. Aquel contingente, animado por la situación y por la ventaja que ahora le proporcionaba el terreno, descendieron imparables por las lomas atacando de flanco a los musulmanes. Situación que recogen expresivamente las crónica castellanas ${ }^{104}$ cuando dicen que esta gente bajaba por «el rrecuesto ayuso matando $e$ firiendo en los moros".

Aquello suponía una situación inesperada para el sultán benimerí que, no obstante, reaccionó dando la orden de detenerlos. Al parecer ${ }^{105}$, dispuso entonces un cambio de posiciones que resultó decisivo cuando, al volverse y avanzar las banderas de la retaguardia benimerí hacia los cristianos que bajaban, los hombres que formaban el grueso de la caballería musulmana y que frenaba a los cristianos que venían desde el Salado por las lomas de El Polear ${ }^{106}$, Las Peñuelas y EI Pinganillo, creyeron que su retaguardia huía ya del campo de batalla y por tal razón se produjo la desbandada general y la consiguiente fuga por el camino hacia Algeciras. Debía ser por entonces alrededor de mediodía - la hora tercia, dice el cardenal Albornoz ${ }^{107}$ - cuando se terminó el enfrentamiento y comenzó el «alcance», termino medieval que señala la persecución de los derrotados y de cuyos resultados nos habla el topónimo tarifeño "Cañada de Matamoros», a pesar de que en nuestros días se pretenda cambiar por el más eufemístico de «Matatoros».

\section{EPÍLOGO}

La victoria del Salado resonó por entonces en toda la Cristiandad. En Castilla, no salían de su asombro al considerar en las condiciones en que se dio y, de hecho, se comenzó a valorar aquella victoria por encima de la obtenida en las Navas de Tolosa, cuando se derrotó a los almohades. Desde luego, en el reino castellano se comenzó a tener conciencia de la trascendencia del momento y todo indica que

103 La presencia de unos y otros sobre el campamento de los benimerines la recoge la Crónica en p. 327 y la Gran Crónica en, tomo II, p. 431.

104 Véase esto en las mismas referencias cronísticas de la nota anterior.

105 Nada se recoge de esta situación en nuestras crónicas porque prestan más atención a la huida del sultán del campo de batalla; sin embargo, «El collar de perlas» —citado en HUICI MIRANDA: Las grandes batallas...., p.380-, sí recoge esta acción que dio pie al desastre final.

106 Para nosotros, el nombre actual de esta loma: «Polear», es una deturpación de «Pelear» porque sobre ella debieron darse los momentos más difíciles del encuentro para el rey de Castilla.

107 Así lo dice en su carta al obispo de Frascati. Véase en BENEYTO PEREZ: El cardenal Albornoz..., p. 331. 
una de las consecuencias directas de este triunfo fue la decisión de Alfonso XI para que se escribiera la crónica de su reinado. Por lo que al Estrecho se refiere, en los dos meses que restaban del año, poco que apuntar si exceptuamos la rápida retirada del ejército cristiano hacia Sevilla por falta de provisiones para mantenerse sobre el terreno, así como la continuidad en aquellas aguas de la flota del reino de Aragón a pesar de no haber colaborado en aquel triunfo.

Pero aquella batalla tuvo otras consecuencias a más largo plazo; éstas dieron como resultado final el que la flota castellana acabara imponiendo su dominio en el Estrecho, pero esta es una cuestión que abordaremos en otro trabajo. 